\title{
LINHA DE CUIDADO AO TRAUMA NO HOSPITAL MUNICIPAL DR JOSÉ DE CARVALHO FLORENCE - PERFIL EPIDEMIOLÓGICO DO PACIENTE ATENDIDO NO ANO DE 2018.
}

Eixo temático: Avaliação e Qualidade do Cuidado

\section{INTRODUÇÃO}

O trauma constitui um dos maiores problemas de saúde pública, sendo responsável por um grande número de óbitos, invalidez prolongada ou permanente principalmente em indivíduos jovens ${ }^{1}$. Porém, o perfil epidemiológico da vítima de trauma vem mudando nos últimos tempos.

\section{OBJETIVOS}

Apresentar a mudança do perfil epidemiológico dos pacientes atendidos pela linha de cuidado ao trauma do Hospital Municipal Dr. José de Carvalho Florence, entre os anos de 2017 e 2018.

\section{METODOLOGIA}

Análise do banco de dados da Linha de Cuidados, no período de janeiro de 2017 a novembro de 2018.

\section{CONCLUSÃO}

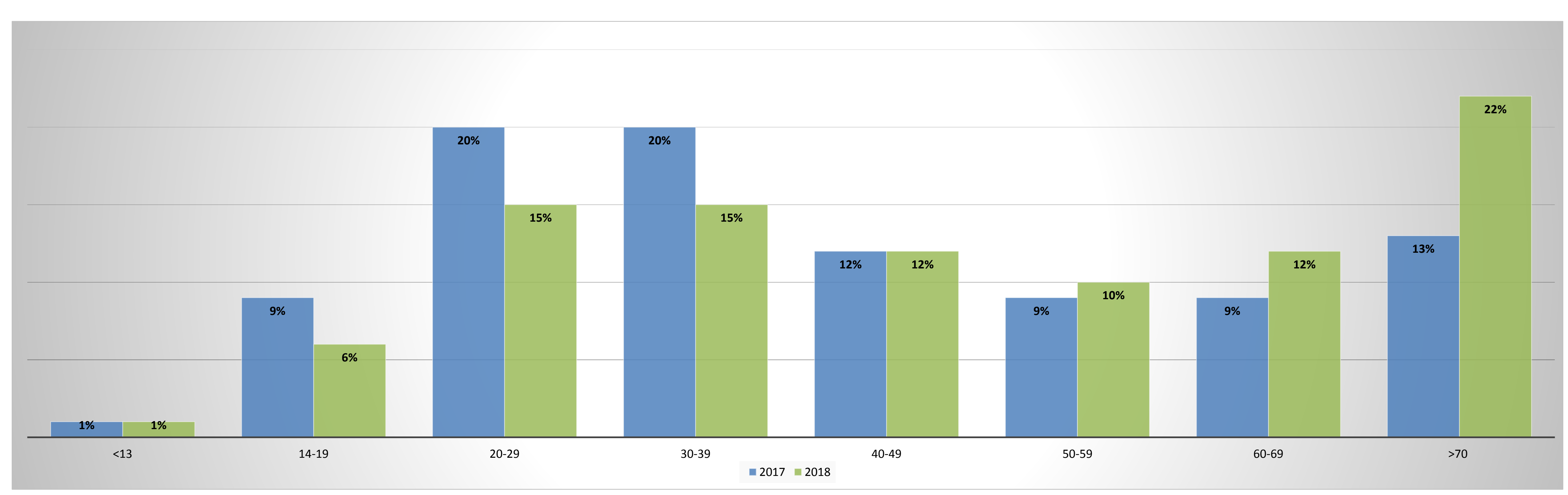

O envelhecimento da população brasileira é um fato natural e irreversível. A realidade socio econômica do brasileiro faz com que a população idosa permaneça cada vez mais no mercado de trabalho, no trânsito e em atividades propensas a acidentes dentro e fora do domicílio. Fez-se necessário a revisão do protocolo institucional de atendimentos e criação de programa municipal de prevenção ao trauma nessa população já que os fatores de risco associados a ela, principalmente as doenças sistêmicas pré-existentes, contribuem para internações mais prolongadas, ocorrência de eventos adversos ao trauma e sobrevida. 